\title{
Phenazine-1-Carboxamide Production in the Biocontrol Strain Pseudomonas chlororaphis PCL1391 Is Regulated by Multiple Factors Secreted into the Growth Medium
}

\author{
Thomas F. C. Chin-A-Woeng, ${ }^{1}$ Daan van den Broek, ${ }^{1}$ Gert de Voer, ${ }^{1}$ Koen M. G. M. van der Drift, ${ }^{2}$ \\ Sietske Tuinman, ${ }^{1}$ Jane E. Thomas-Oates, ${ }^{2,3}$ Ben J. J. Lugtenberg, ${ }^{1}$ and Guido V. Bloemberg ${ }^{1}$ \\ ${ }^{1}$ Leiden University, Institute of Molecular Plant Sciences, Clusius Laboratory, Wassenaarseweg 64, $2333 \mathrm{AL}$ \\ Leiden, The Netherlands; ' $D$ Department of Biomolecular Mass Spectrometry, Faculty of Chemistry, Utrecht \\ University, Sorbonnelaan 16, 3584 CA Utrecht, The Netherlands; ${ }^{3}$ Michael Barber Centre for Mass \\ Spectrometry, Department of Chemistry, University of Science and Technology in Manchester (UMIST), \\ P.O. Box 88, Manchester M60 1QD, U.K. \\ Submitted 29 December 2000; Accepted 25 April 2001.
}

Pseudomonas chlororaphis PCL1391 controls tomato foot and root rot caused by Fusarium oxysporum f. sp. radicislycopersici. The production of phenazine-1-carboxamide (PCN) is crucial for this biocontrol activity. In vitro production of PCN is observed only at high-population densities, suggesting that production is under the regulation of quorum sensing. The main autoinducer molecule produced by PCL1391 was identified structurally as $N$ hexanoyl-L-homoserine lactone $\left(\mathrm{C}_{6}-\mathrm{HSL}\right)$. The two other autoinducers that were produced comigrate with $N$ butanoyl-L-homoserine lactone $\left(\mathrm{C}_{4}\right.$-HSL) and $\mathrm{N}$-octanoylL-homoserine lactone $\left(\mathrm{C}_{8}\right.$-HSL). Two PCL1391 mutants lacking production of $\mathrm{PCN}$ were defective in the genes $p h z I$ and $p h z R$, respectively, the nucleotide sequences of which were determined completely. Production of PCN by the phzI mutant could be complemented by the addition of exogenous synthetic $\mathrm{C}_{6}$-HSL, but not by $\mathrm{C}_{4}$-HSL, $\mathrm{C}_{8}$-HSL, or any other HSL tested. Expression analyses of Tn5luxAB reporter strains of $p h z I, p h z R$, and the $p h z$ biosynthetic operon clearly showed that phzI expression and PCN production is regulated by $\mathrm{C}_{6}$-HSL in a population densitydependent manner. The introduction of multiple copies of the regulatory genes $p h z I$ and $p h z R$ on various plasmids resulted in an increase of the production of HSLs, expression of the PCN biosynthetic operon, and consequently, PCN production, up to a sixfold increase in a copydependent manner. Surprisingly, our expression studies show that an additional, yet unidentified factor(s), which are neither PCN nor $\mathrm{C}_{4}$-HSL or $\mathrm{C}_{8}$-HSL, secreted into the growth medium of the overnight cultures, is involved in the positive regulation of phzI, and is able to induce PCN

Corresponding author: T. F. C. Chin-A-Woeng;

Telephone: +31 71 5275072; Fax: +31 71 5275088;

E-mail: chin@ rulbim.leidenuniv.nl

Current address of K. M. G. M. Van der Drift: Washington University Center for Biomedical and Bioorganic Mass Spectrometry, Department of Chemistry, Campus Box 1134, One Brookings Drive, St. Louis, MO 63130, U.S.A. biosynthesis at low cell densities in a growing culture, resulting in an increase of $\mathrm{PCN}$ production.

Additional keywords: biofungicide, luxI, phenazine, plant growth-promoting rhizobacteria, signal molecules.

The tomato rhizosphere isolate Pseudomonas chlororaphis PCL1391 exhibits biocontrol activity against Fusarium oxysporum (Schlechtend.:Fr.) f. sp. radicis-lycopersici (W. R. Jarvis \& Shoemaker), the causal agent of tomato foot and root rot. The production of phenazine-1-carboxamide (PCN), including the last step, conversion of phenazine-1-carboxylic acid (PCA) to PCN, was shown to be essential for the biocontrol activity of strain PCL1391 (Chin-A-Woeng et al. 1998). PCN production is maximal at the end of the exponential growth phase, suggesting that the production is mediated through a population density-dependent regulation mechanism known as quorum sensing. In quorum sensing, a key role is played by a small diffusible signal molecule, or autoinducer. In many gram-negative bacteria, the process of quorum sensing is activated when the overall concentration of $\mathrm{N}$-acylhomoserine lactone (HSL) signal molecules exceeds a certain threshold concentration (Fuqua et al. 1994; Salmond et al. 1995). The population density-dependent HSL signal molecule interacts with its cognate transcriptional regulator, a LuxR homolog. In Pseudomonas aeruginosa, it was shown that $\mathrm{C}_{4^{-}}$ HSL diffuses freely across the cellular membrane into the local environment, whereas 3- $N$-oxo-dodecanoyl-L-homoserine lactone (3-oxo- $\mathrm{C}_{12}$-HSL) reaches the environment through an active efflux (Pearson et al. 1999). In the tra system, binding of the activated complex TraR-3-oxo- $\mathrm{C}_{8}$-HSL to target promoters subsequently induces gene expression (Zhu and Winans 1999). The autoinducer synthase often is regulated by an autoregulatory loop that, once initiated, results in amplification of the signal (Salmond et al. 1995).

Recently, we described a structural gene cluster phzA to $p h z H$ that is responsible for the biosynthesis of PCN in which the last gene, $p h z H$, directs the conversion of PCA to PCN 
(Chin-A-Woeng et al. 2001). In this paper, we describe the i) structural identification of $\mathrm{C}_{6}-\mathrm{HSL}$ as the main HSL produced by PCL1391; ii) identification and characterization of regulatory genes $p h z I$ and $p h z R$ affecting PCN production; iii) construction and expression analyses of $\operatorname{lu} x A B$ reporter strains of $p h z I, p h z R$, and the $p h z$ biosynthetic operons; iv) identification of $\mathrm{C}_{6}$-HSL as the autoinducer of PCN biosynthesis; v) overproduction of PCN by the introduction of multiple copies of the $p h z I$ and $p h z R$ genes; and vi) indication of the presence of a second, yet unidentified factor in spent growth medium of PCL1391, which can advance and increase PCN biosynthesis.

\section{RESULTS}

\section{Purification and identification of autoinducers produced by $P$. chlororaphis.}

Production of PCN in P. chlororaphis PCL1391 (Table 1) is observed only in cultures with high population density and therefore likely to be subject to quorum sensing. To analyze the production of autoinducer(s) by strain PCL1391, a crude dichloromethane extract of spent culture medium of a 72-h culture was tested for induction of a number of quorumsensing reporter systems, including those for Chromobacterium violaceum pigmentation (cvi) (McClean et al. 1997), Vibrio fischeri luminescence (lux) (Stevens and Greenberg 1997), and Agrobacterium tumefaciens conjugation (tra) (Hwang et al. 1995). After separation with $\mathrm{C}_{18}$ thin-layer chromatography (TLC), three spots were detected in the Chromobacterium spp. overlay system (Fig. 1, lane 4). One major spot with $\mathrm{R}_{\mathrm{f}}$ value 0.4 migrated to the same position as synthetic $\mathrm{C}_{6}$-HSL (Fig. 1, lane 2). A second spot with a $\mathrm{R}_{\mathrm{f}}$ value of 0.57 , which migrated to the same position as synthetic $\mathrm{C}_{4}$-HSL, was detected (Fig. 1, lane 1). A third spot with a $R_{f}$ value 0.13 comigrated with synthetic $C_{8}$-HSL (Fig. 1, lane 3). Extracts of spent culture supernatant also were able to induce the lux system, although they induced only weak signals in the tra system (data not shown). None of the reporter systems was induced by dichloromethane extracts of uninoculated King's B (KB) (King et al. 1954) or Luria-Bertani (LB) growth medium.

To overcome the problem of copurification of autoinducer(s) and PCN in the wild type, strain PCL1119 (phzB::Tn5luxAB) (Chin-A-Woeng et al. 1998), a PCL1391 derivative unable to produce PCN as a result of a mutation in the biosynthetic $p h z B$ gene, was used for autoinducer purification. PCL1119 is not changed in its autoinducer production compared with the wild-type strain, as analyzed by TLC (data not shown). The compound migrating with $\mathrm{R}_{\mathrm{f}}$ value 0.4 was purified with $\mathrm{C}_{18}$-reverse phase high-pressure liquid chromatography (HPLC) and analyzed with positive ion mode nanoelectrospray collision-induced dissociation (CID) tandem mass spectrometry on a hybrid quadrupole time-of-flight (QTOF) mass spectrometer, which allows exceptional sensitivity in the tandem mode. Instrument conditions were optimized with a solution of $1.3 \mathrm{ng}$ of standard $\mathrm{C}_{6}$-HSL per $\mu \mathrm{l}$, having a concentration approximately one-tenth of that necessary to give a response in the bioassay similar to that of the fraction isolated from strain PCL1391. Following optimization, a CID spectrum in which fragmentation is induced on collision with a positive pressure of argon from the standard was recorded (Fig. 2A). The needle containing the standard was then discarded, and a CID spectrum was recorded of the same precur-

Table 1. Microorganisms and plasmids

\begin{tabular}{|c|c|c|}
\hline Strains-plasmids & Relevant characteristics & Reference or source \\
\hline \multicolumn{3}{|l|}{ Bacterial strains } \\
\hline PCL1391 & $\begin{array}{l}\text { Wild-type Pseudomonas chlororaphis, producing phenazine-1-carboxamide and biocontrol } \\
\text { strain of tomato foot and root rot caused by Fusarium oxysporum f. sp. radicis- } \\
\text { lycopersici }\end{array}$ & Chin-A-Woeng et al. 1998 \\
\hline PCL1392 & PCL1391 derivative tagged with $\mathrm{Tn} 5$ lacZ, $\mathrm{Km}^{\mathrm{R}}$, with wild-type colonizing ability & Chin-A-Woeng et al. 2000 \\
\hline PCL1103 & PCL1391 derivative in which a Tn5-promoterless $l u x A B$ has been inserted in $p h z I$ & This study \\
\hline PCL1104 & PCL1391 derivative in which a Tn5-promoterless $l u x A B$ has been inserted in $p h z R$ & This study \\
\hline PCL1119 & PCL1391 derivative in which a Tn5-promoterless $\operatorname{lux} A B$ has been inserted in $p h z B$ & Chin-A-Woeng et al. 1998 \\
\hline DH5 $\alpha$ & $\begin{array}{l}\text { supE44 } \Delta \text { lac } \mathrm{U} 169(\Phi 80 \text { lacZLM15) hsdR17 recAl endA1 gyrA96 thi } 1 \text { relA1; general- } \\
\text { purpose Escherichia coli host strain used for transformation and propagation of plasmids }\end{array}$ & Boyer and Roulland-Dussoix 1969 \\
\hline CV026 & Chromobacterium violaceum $N$-acyl-homoserine lactone (HSL) reporter strain & Milton et al. 1997 \\
\hline NT1(pJM749) & $\begin{array}{l}\text { Agrobacterium tumefaciens NT1 HSL reporter strain harboring pJM } 749 \text { containing a lacZ } \\
\text { reporter fused to a tra gene of which expression is dependent on TraR }\end{array}$ & Piper et al. 1993 \\
\hline \multicolumn{3}{|c|}{${ }^{1}$} \\
\hline pRL1063a & Plasmid harboring $\operatorname{Tn} 5$ transposon containing promoterless $\operatorname{lux} A B$ & Wolk et al. 1991 \\
\hline pBBR1MCS-5 & Gentamycin-resistant derivative of the broad-host-range cloning vector pBBR1MCS & Kovach et al. 1995 \\
\hline pME6010 & E. coli/Pseudomonas spp. shuttle vector, stably maintained in Pseudomonas spp., $\mathrm{Tc}^{\mathrm{R}}$ & Heeb et al. 2000 \\
\hline pMP6003 & $\begin{array}{l}\text { pRL1063a-based plasmid recovered from chromosomal DNA of PCL1103 after digestion } \\
\text { with EcoRI }\end{array}$ & This study \\
\hline pMP6004 & $\begin{array}{l}\text { pRL1063a-based plasmid recovered from chromosomal DNA of PCL1104 after digestion } \\
\text { with EcoRI }\end{array}$ & This study \\
\hline pMP6007 & $\begin{array}{l}\text { pBluescript containing a } 4.5-\mathrm{kb} \text { chromosomal fragment of strain PCL1391 with the } p h z I \text { and } \\
p h z R \text { genes and the first part of the } p h z A \text { gene }\end{array}$ & This study \\
\hline pMP4062 & $\begin{array}{l}\text { Rhizosphere-stable plasmid pME6010 containing a 4.5-kb EcoRI fragment with the } p h z I \\
\text { and } p h z R \text { genes of strain PCL1391 }\end{array}$ & This study \\
\hline pMP4065 & $\begin{array}{l}\text { pBBR1MCS-5 containing a } 2.9 \mathrm{~kb} E c o \mathrm{RI} / \text { Bam HI fragment with the } p h z I \text { and } p h z R \text { genes of } \\
\text { strain PCL1391 subcloned from the } 4.5-\mathrm{kb} \text { chromosomal fragment in pMP6007 }\end{array}$ & This study \\
\hline pMP4067 & $\begin{array}{l}\text { The stable plasmid pME6010 containing a 2.9-kb HindIII with the } p h z I \text { and } p h z R \text { genes of } \\
\text { strain PCL1391 }\end{array}$ & This study \\
\hline pSB401 & Autoinducer reporter construct based upon the Vibrio bioluminescence (lux) system & Winson et al. 1998 \\
\hline pBluescript & General-purpose cloning vector, $\mathrm{Cb}^{\mathrm{R}}$ & Stratagene, La Jolla, CA, U.S.A. \\
\hline
\end{tabular}


sor ion mass, yet only introduced solvent in order to be certain that no contamination of the instrument had occurred with the standard and to identify any background signals arising from the solvent. No ions corresponding to $\mathrm{C}_{6}$-HSL were observed in this blank spectrum, although an ion at $m / z 107$, also observed in the $\mathrm{C}_{6}$-HSL spectrum, was present. The bioactive fraction was then introduced into the mass spectrometer in a fresh needle, and a mass spectrum was recorded. Very weak pseudomolecular ions were observed at $\mathrm{m} / \mathrm{z} 200\left(\mathrm{M}+\mathrm{H}^{+}\right)$and $222\left(\mathrm{M}+\mathrm{Na}^{+}\right)$for a species with a molecular mass corresponding to $\mathrm{C}_{6}$-HSL. These ions were barely discernible above the background. A CID spectrum of the $\mathrm{M}+\mathrm{H}^{+}$ion at $\mathrm{m} / \mathrm{z} 200$, however, was recorded and generated a good-quality spectrum (Fig. 2B) that was very similar to the one obtained from the standard $\mathrm{C}_{6}$-HSL (Fig. 2A). Fragment ions characteristic of $\mathrm{C}_{6}$-HSL were observed at $m / z, 99,102,172$, and 182 (Fig. 2A inset). The ions at $\mathrm{m} / \mathrm{z}, 99$ and 102 were generated on fragmentation of the amide bond between the hexanoyl moiety and the homoserine lactone, with the ion at $\mathrm{m} / \mathrm{z} 99$ corresponding to the hexanoyl substituent and that at $m / z, 102$ being characteristic of the homoserine lactone. The ions at $\mathrm{m} / z 172$ and 182 arise by the loss of small neutrals $\left(m / z, 172=\mathrm{M}+\mathrm{H}^{+}-\mathrm{C}_{2} \mathrm{H}_{4}\right.$; $\left.m / z, 182=\mathrm{M}+\mathrm{H}^{+}-\mathrm{H}_{2} \mathrm{O}\right)$. These results clearly demonstrate that the component in the major bioactive fraction is $\mathrm{N}$ hexanoyl-L-homoserine lactone $\left(\mathrm{C}_{6}\right.$-HSL).

In dichloromethane extracts of spent culture supernatant, the other two activities were present in small amounts that were not sufficient for mass spectrometric analyses and, thus, tentatively assigned as $N$-butanoyl-L-homoserine lactone $\left(\mathrm{C}_{4}-\mathrm{HSL}\right)$ and $\mathrm{N}$-octanoyl-L-homoserine lactone $\left(\mathrm{C}_{8^{-}}\right.$ HSL) on the basis of their TLC migration behavior (Fig. 1) and their biological activities in the cvi, lux, and tra reporter systems.

\section{Isolation and characterization of mutants affected in PCN biosynthesis.}

Screening of 18,000 Tn5luxAB PCL1391 transconjugants on agar plates and in liquid cultures resulted in the isolation of eight mutants altered in PCN production, as judged by their altered pigmentation. Four mutants were identified in which the transposon was not inserted in a PCN biosynthetic gene, two of which are described in this paper. The regions flanking the Tn5 insertion in these two mutants, PCL1103 and PCL1104, were recovered in plasmids pMP6003 and pMP6004, respectively. Nucleotide sequence analyses of the flanking regions showed that the transposons in these mutants were inserted in homologs of $\operatorname{luxI}$ and $l u x R$, respectively. Because the homologous genes are involved in PCN biosynthesis, we named them $p h z I$ and $p h z R$, respectively. The transposons were inserted at nucleotide position 348 and 620 of the $p h z I$ and $p h z R$ genes, respectively. These sequence data have been submitted to the DDBJ, EMBL, and GenBank databases under accession no. AF195615.

\section{Characterization of $p h z I$ and $p h z R$ mutants.}

The production of PCN by PCL1103 (phzI::Tn5luxAB) and PCL1104 (phzR::Tn5luxAB) was determined with TLC and HPLC. PCN was not detected in the toluene extracts of strain PCL1103 (phzI::Tn5luxAB) and PCL1104 (phzR::Tn5luxAB) (data not shown), nor were any autoinducers detected in dichloromethane extracts of these strains (data not shown). PCN production in the phzI mutant was restored to wild-type levels by the addition of either spent growth medium from PCL1119 ( $p h z B:: \operatorname{Tn} 5$ lux $A B$ ) or synthetic $\mathrm{C}_{6}$-HSL (data not shown). The $p h z I$ and $p h z R$ mutants were not altered in the production of hydrogen cyanide $(\mathrm{HCN})$, protease, and chitinase (Table 2). Neither mutant was impaired in motility or in their ability to colonize the tomato root tip in competition with the parental strain, as judged after coinoculation of seeds with a lacZtagged derivative of wild-type strain PCL1391 in a 1:1 ratio (data not shown). Strains PCL1103 (phzI::Tn5luxAB) and PCL1104 (phzR::Tn5luxAB) were unable to inhibit growth of F. oxysporum f. sp. radicis-lycopersici in an in vitro antifungal assay (data not shown), which is consistent with the observed lack of PCN production.

\section{Isolation and characterization of $l u x I$ and $l u x R$ homologs of strain PCL1391.}

To isolate a chromosomal fragment of strain PCL1391 containing luxI and luxR homologs, an EcoRI chromosomal library was transformed to DH5 $\alpha$ harboring pSB401, a HSLdependent reporter construct based upon the Vibrio lux system (McClean et al. 1997). Plasmid pMP6007 appeared to induce the reporter and contained a 4.5-kb chromosomal fragment of strain PCL1391. Nucleotide sequencing of this clone revealed the complete $p h z I$ and $p h z R$ genes and the promoter and first

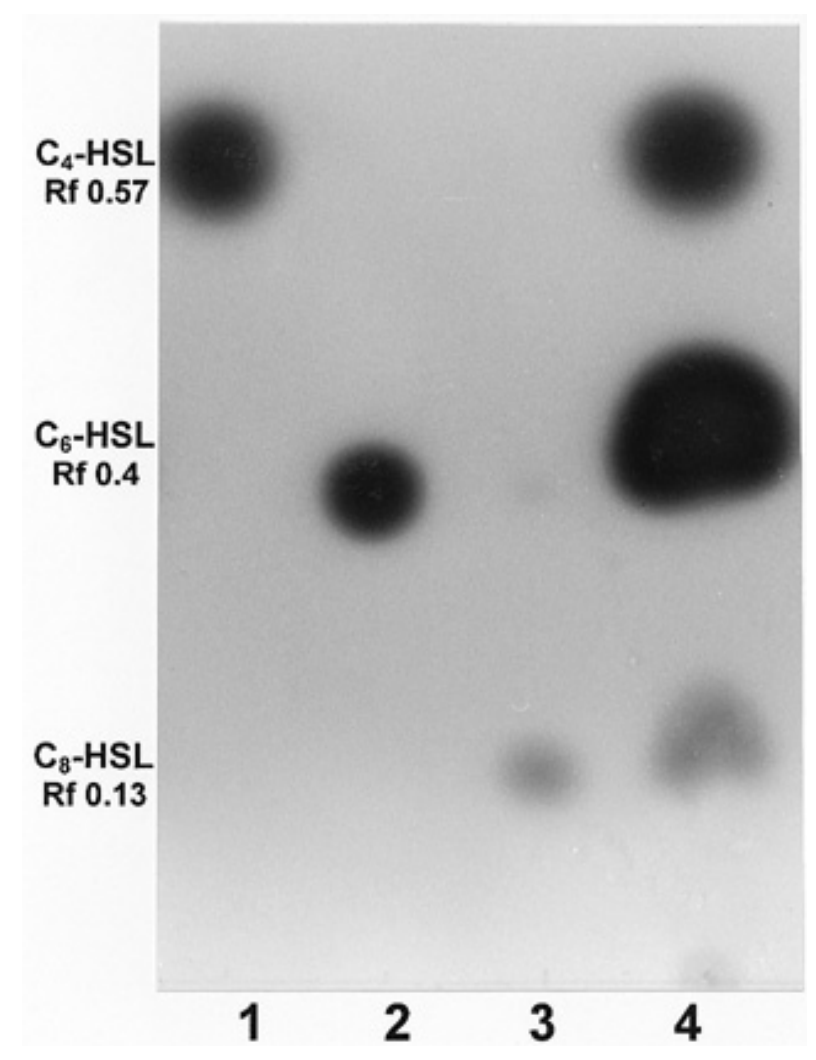

Fig. 1. $\mathrm{C}_{18}$-reverse phase thin-layer chromatography analysis of $\mathrm{N}$-acylL-homoserine lactones produced by Pseudomonas chlororaphis strain PCL1391 visualized with the Chromobacterium violaceum reporter assay. Lane 1: synthetic $\mathrm{C}_{4}$-HSL standard; lane 2: synthetic $\mathrm{C}_{6}$-HSL standard; lane 3: synthetic $\mathrm{C}_{8}$-HSL standard; lane 4: autoinducer profile of strain P. chlororaphis PCL1391. Note that the major spot visible in lane 4 moved to exactly the same position as $\mathrm{C}_{6}-\mathrm{HSL}$ when a smaller amount of sample was applied. 
part of $p h z A$, the first gene of the PCN biosynthetic operon (Fig. 3) (Chin-A-Woeng et al. 1998).

Escherichia coli strain DH5 $\alpha$ harboring pMP6007 induced the DH5 $\alpha[\mathrm{pSB} 401]$ and Chromobacterium spp. CV026 reporter strains when streaked in the vicinity of the reporter, indicating the production of a diffusible HSL. To test whether $p h z I$ and $p h z R$ are responsible for the synthesis of $\mathrm{C}_{6}-\mathrm{HSL}$, culture supernatants of $E$. coli $\mathrm{DH} 5 \alpha$, with and without pMP6007, were extracted with dichloromethane and subjected to TLC analysis. Autoinducer activity with $\mathrm{R}_{\mathrm{f}}$ value identical to $\mathrm{C}_{6}$-HSL produced by wild-type PCL1391 was detected only in strains harboring pMP6007 (data not shown).

To transfer the $p h z I$ and $p h z R$ genes to PCL1391 mutant derivatives, plasmid pMP4062 was constructed by transfer of the 4.5-kb EcoRI chromosomal fragment containing the phzI and $p h z R$ genes of strain PCL1391 from pMP6007 to pME6010, a shuttle vector maintained stably in Pseudomonas spp., without antibiotic pressure (Heeb et al. 2000). After pMP4062 was introduced into strains PCL1103 (phzI::Tn5luxAB) and PCL1104 (phzR::Tn5luxAB), PCN production was restored to wild-type levels and resulted in increased production in both mutants, as analyzed on TLC analysis of culture supernatants (data not shown). This result, together with the mutant studies of strain PCL1103 (phzI::Tn5luxAB) and PCL1104 ( $p h z R:: \operatorname{Tn} 5$ lux $A B$ ), shows that PhzI and PhzR are required for autoinducer synthesis.

Sequence analysis of the open reading frames shows that the $p h z I$ and $p h z R$ genes are convergently transcribed, with $p h z I$ being transcribed in the same direction as the $p h z$ biosynthetic operon (Fig. 3A). The deduced $p h z I$ and $p h z R$ gene products of PCL1391 were most homologous with the phzI (Fig. 3B) and phzR (Fig. 3C) gene products in the PCAproducing strains Pseudomonas aureofaciens 30-84 (95 and 96\% identity, respectively) and Pseudomonas fluorescens 2-79 (85 and 87\% identity, respectively) (Mavrodi et al. 1997; Wood et al. 1997). Similarity to additional LuxI and LuxR homologs in other Pseudomonas and bacterial species was much less (20 to $40 \%$ ).

In the promoter regions of the $p h z A$ homologous genes of $P$. chlororaphis, $P$. aureofaciens, and $P$. fluorescens, a strictly conserved 18-bp palindromic sequence was identified (Fig. 3D). A similar conserved sequence also was observed in the promoter regions of the phzI genes of the three species (Fig. 3D). In V. fischeri, a 20-bp palindromic sequence was thought to constitute the binding site for the LuxR regulatory protein. Because the palindromic sequences lack similarity with the lux box in the promoter regions of the lux and las genes, we named the lux box-like sequences phz boxes.

\section{Influence of exogenous autoinducers on the expression} of the $p h z I$ and $p h z R$ genes and the biosynthetic operon.

Previously, a number of biosynthetic mutants have been identified from which mutant PCL1119 contains a promoterless $\operatorname{lux} A B$ reporter in the $p h z B$ gene. Strain PCL1119 was used for expression studies in the tomato rhizosphere, showing that the biosynthetic operon is expressed in vivo (Chin-A-
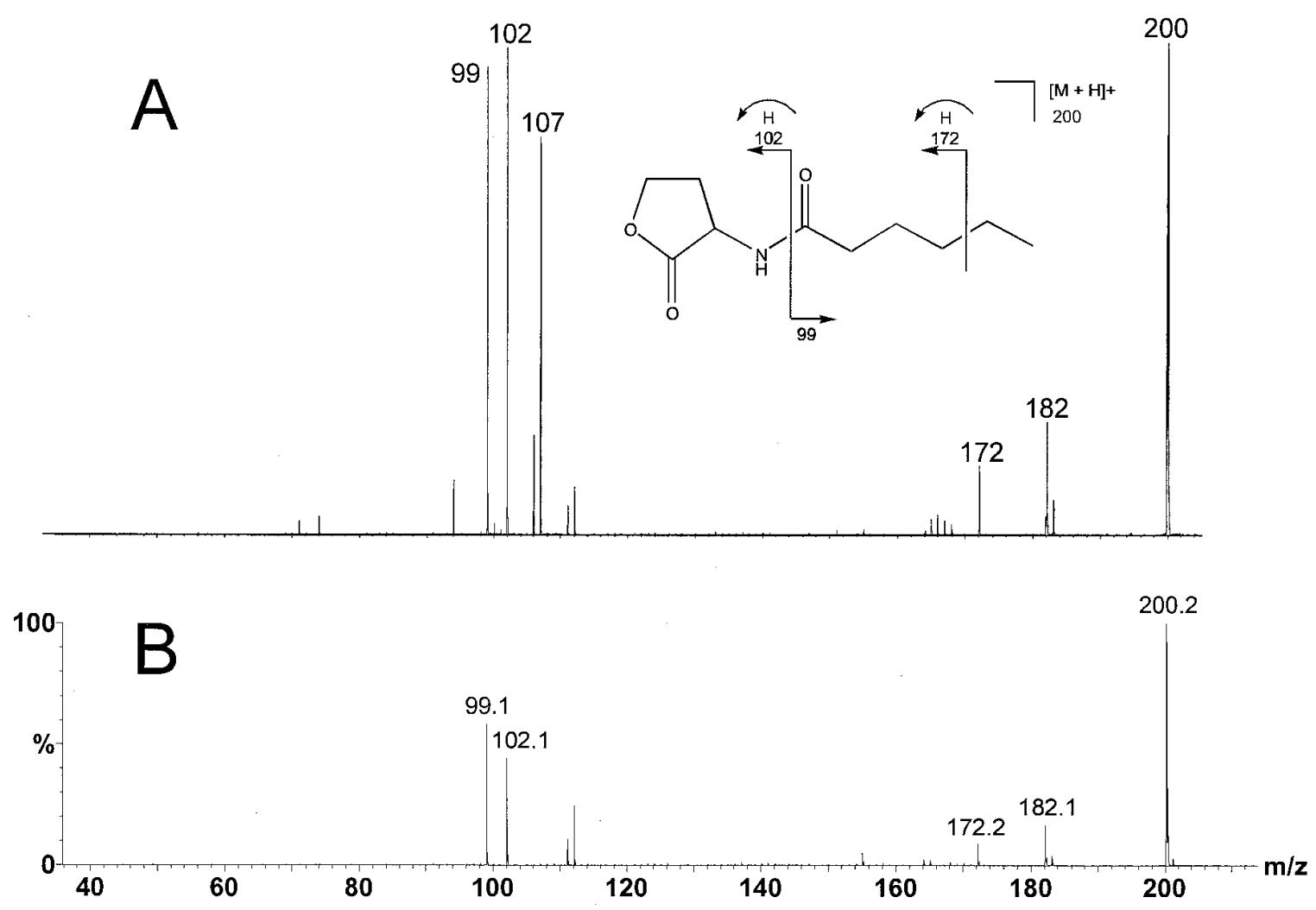

Fig 2. Structural identification of the major compound exhibiting autoinducer activity produced by Pseudomonas chlororaphis PCL1391 by mass spectrometry. A, Collision-induced dissociation (CID) spectrum obtained from a $1.3 \mathrm{ng}$ of standard solution of synthetic $\mathrm{C}_{6}$-HSL per ml. Insert, Fragmentation scheme for $\mathrm{C}_{6}$-HSL. B, CID spectrum obtained from a high-pressure liquid chromatography fraction corresponding with the autoinducer activity with $\mathrm{R}_{\mathrm{f}} 0.4$ on $\mathrm{C} 18$ reverse-phase thin-layer chromatography (Fig. 1). 
Woeng et al. 1998). This strain was used to quantify the expression of the PCN biosynthetic operon during growth in liquid cultures under various conditions. Similarly, expression of the phzI and $p h z R$ genes that mutated in PCL1103 (phzI::Tn5luxAB) and PCL1104 (phzR::Tn5luxAB) could be quantified because the promoterless $\operatorname{lux} A B$ genes were inserted in the same orientation as the direction of transcription. Expression of the phzI gene in mutant PCL1103 remained at a basal level during growth, indicating that inducing activity is absent without a functional phzI. The addition of synthetic $\mathrm{C}_{6^{-}}$ HSL or spent growth medium of an overnight culture of PCL1391 to a cell culture of optical density (OD) at $620 \mathrm{~nm}$ of 0.1 of PCL1103 resulted in an induction of phzI expression, once the cell culture grew to $\mathrm{OD}_{620}$ of 0.6 or more (Fig. 4A). Expression of $p h z R$ in mutant PCL1104 was constitutive in the presence of exogenous $\mathrm{C}_{6}$-HSL as well as in the absence of endogenous autoinducers, although the presence of exogenous $\mathrm{C}_{6}$-HSL increased expression (Fig. 4B). Expression of the PCN biosynthetic gene cluster (phzB::Tn5luxAB) in PCL1119 was increased greatly in the late exponential-early stationary phase, and the moment of induction could be advanced by the addition of synthetic $\mathrm{C}_{6}$-HSL (Fig. 4C), but not by the addition of other synthetic HSLs $\left(\mathrm{C}_{4}-\mathrm{HSL}, \mathrm{C}_{8}-\mathrm{HSL}, \mathrm{C}_{10^{-}} \mathrm{HSL}, \mathrm{C}_{12^{-}}\right.$ HSL, 3-oxo- $\mathrm{C}_{6}$-HSL, 3-oxo- $\mathrm{C}_{8}$-HSL, or 3-oxo- $\mathrm{C}_{10}$-HSL) (data not shown).

The addition of cell-free spent culture medium of the HSLproducing strain PCL1119 ( $p h z B:: \operatorname{Tn} 5$ lux $A B$ ) to a fresh culture of strain PCL1103 (phzI::Tn5luxAB) resulted in a twofold and earlier induction of the $p h z I$ gene than what occurred after the addition of synthetic $\mathrm{C}_{6}$-HSL (Fig. 4C). Although the addition of spent culture medium of an overnight culture of strain PCL1103 did not induce the phzI gene, a synergistic effect was observed when it was added with $\mathrm{C}_{6}$-HSL (Fig. 4D). Expression induction in the presence of the culture supernatant of strain PCL1103 was already in midexponential-phase growth $\left(\mathrm{OD}_{620}\right.$ of 0.35$)$, much earlier than in the presence of $\mathrm{C}_{6}$-HSL alone (Fig. 4D). Combinations of autoinducers produced by strain PCL1391 were tested for their possible synergistic effect on expression. None of the combinations, $\mathrm{C}_{4}{ }^{-}$ $\mathrm{HSL}-\mathrm{C}_{6}-\mathrm{HSL}, \mathrm{C}_{6}-\mathrm{HSL}-\mathrm{C}_{8}-\mathrm{HSL}$, or $\mathrm{C}_{4}-\mathrm{HSL}-\mathrm{C}_{6}-\mathrm{HSL}-\mathrm{C}_{8}-$ HSL resulted in a different level or point of onset of induction than what was observed after the addition of $\mathrm{C}_{6}$-HSL only (data not shown).

\section{Influence of increased $p h z I$ and $p h z R$ copy numbers on the expression of the phz operon.}

To analyze the possibility of increasing PCN production by introducing additional copies of the $p h z I$ and $p h z R$ regulatory genes, a 2.9-kb PCL1391 chromosomal fragment containing these genes was subcloned from pMP6007 into plasmids pME6010 (resulting in pMP4067) and pBBR1MCS-5 (resulting in pMP4065). In Pseudomonas spp., pME6010 is maintained at approximately four to eight copies per cell (Heeb et al. 2000) and pBBR1MCS derivatives are assumed to be present in 30 to 40 copies per cell in E. coli and Bordetella bronchiseptica (Antoine and Locht 1992). An increased production of $\mathrm{C}_{6}$-HSL produced by PCL1391 harboring pME4067 or pME4065 was observed from which the latter produced the largest amount (an estimated tenfold) compared with the wild type, as indicated by the analyses of spent growth supernatant extracts with Chromobacterium spp. indicator assay (data not shown). Subsequently, plasmids were transferred to the bioluminescent reporter PCL1103 (phzI::Tn5luxAB ) for phzI expression studies and to reporter PCL1119 ( $p h z B:: \operatorname{Tn} 5$ luxAB) to analyze expression of the $p h z$ operon. Strain PCL1103 harboring pMP4065 (a "high" copy number) already was induced at a population density of $\mathrm{OD}_{620}$ of 0.2 and expression was four times higher than strain PCL1103 harboring pMP4067 (an "intermediate" copy number) (Fig. 4E). The use of the PCL1103 (phzI::Tn5luxAB) reporter harboring pMP4067 also shows that phzI is much higher expressed than is the control with synthetic $\mathrm{C}_{6}$-HSL added (Fig. 4E). The introduction of multiple copies of the $p h z I$ and $p h z R$ genes into strain PCL1119 (phzB::Tn5luxAB) resulted in an elevated and earlier expression of the $p h z$ operon (Fig. 4F). Expression of the $p h z$ operon in PCL1119 harboring pMP6065 (a high copy number) was slightly higher than PCL1119 harboring pMP4067 (an intermediate copy number). In both strains, the phz genes were at least ten times higher expressed than they were in the empty PCL1119. Because the highest production of $\mathrm{C}_{6}$-HSL and the highest expression of the $p h z I$ and $p h z$ genes was observed in PCL1391 harboring pMP4065, spent culture supernatants of this strain were analyzed with HPLC to quantify the amount of PCN produced. A 6.3-fold production increase was observed compared with the wild type (data not shown).

\section{DISCUSSION}

PCN production is essential for the biocontrol activity of $P$. chlororaphis PCL1391 (Chin-A-Woeng et al. 1998). The first indication that PCN biosynthesis in strain PCL1391 is population density regulated came from the observation that initiation of its production was at the start of the stationary phase. This was confirmed by the observed induction of expression upon reaching the stationary phase with reporter strain PCL1119 ( $p h z B:: T n 5 l u x A B$ ) (Fig. 4C). Quorum sensing usually is regulated by two proteins that belong to the LuxI and LuxR family of two-component regulatory systems. LuxI homologs are assumed to be HSL synthases, which utilize $S$ adenosylmethionine and specific acylated carrier proteins to synthesize HSL signal molecules (Hanzelka and Greenberg 1996). Indeed, homologs of $l u x I$ and $l u x R$, designated $p h z I$ and

Table 2. Characteristics of Pseudomonas chlororaphis PCL1391 transposon derivatives

\begin{tabular}{|c|c|c|c|}
\hline \multirow[b]{2}{*}{ Traits } & \multicolumn{3}{|c|}{ Bacterial strains } \\
\hline & PCL1391 & PCL1103 & PCL1104 \\
\hline Mutated gene & None & $p h z I$ & $p h z R$ \\
\hline PCN production & $t^{\mathrm{a}}$ & $-^{\mathrm{a}}$ & - \\
\hline Antifungal activity ${ }^{\mathrm{b}}$ & + & - & - \\
\hline Autoinducer production & + & - & - \\
\hline $\mathrm{HCN}$ production & + & + & + \\
\hline Protease production & + & + & + \\
\hline Chitinase production & + & + & + \\
\hline Motility & + & + & + \\
\hline Tomato root tip colonization $^{c}$ & + & + & + \\
\hline \multicolumn{4}{|c|}{$\begin{array}{l}\text { a wild-type level; }- \text { : absent } \\
\text { b Activity was tested in a petri dish assay for antifungal activity (Geels } \\
\text { and Schippers 1983) against Fusarium oxysporum f. sp. radicis- } \\
\text { lycopersici }\end{array}$} \\
\hline
\end{tabular}


$p h z R$, respectively, were identified in strain PCL1391 (Fig. 3) and involved in population density-dependent regulation of PCN biosynthesis (Table 2).

Autoinducer production was shown with the use of HSL reporter assays (Fig. 1). The major autoinducer was identified structurally as $N$-hexanoyl-L-homoserine lactone by nanoelectrospray Q-TOF mass spectrometry (Fig. 2). In addition, strain PCL1391 produces two other autoinducers that comigrate with synthetic $\mathrm{C}_{4}$-HSL and $\mathrm{C}_{8}$-HSL. The latter two com- pounds evidently do not play a role in $\mathrm{PCN}$ production and may be synthesized as the result of a somewhat loose specificity for the acyl-acyl carrier protein (ACP) substrate during $\mathrm{C}_{6^{-}}$ HSL biosynthesis. In vitro work with TraI and LuxI has shown that these synthases can synthesize acyl-HSL signals with different chain lengths and even C-3 substitutions (Parsek et al. 1999; Schaefer et al. 1997). In strain PCL1391, the phzI and $p h z R$ genes are transcribed convergently and their organization, localization (Fig. 3A), and nucleotide and deduced
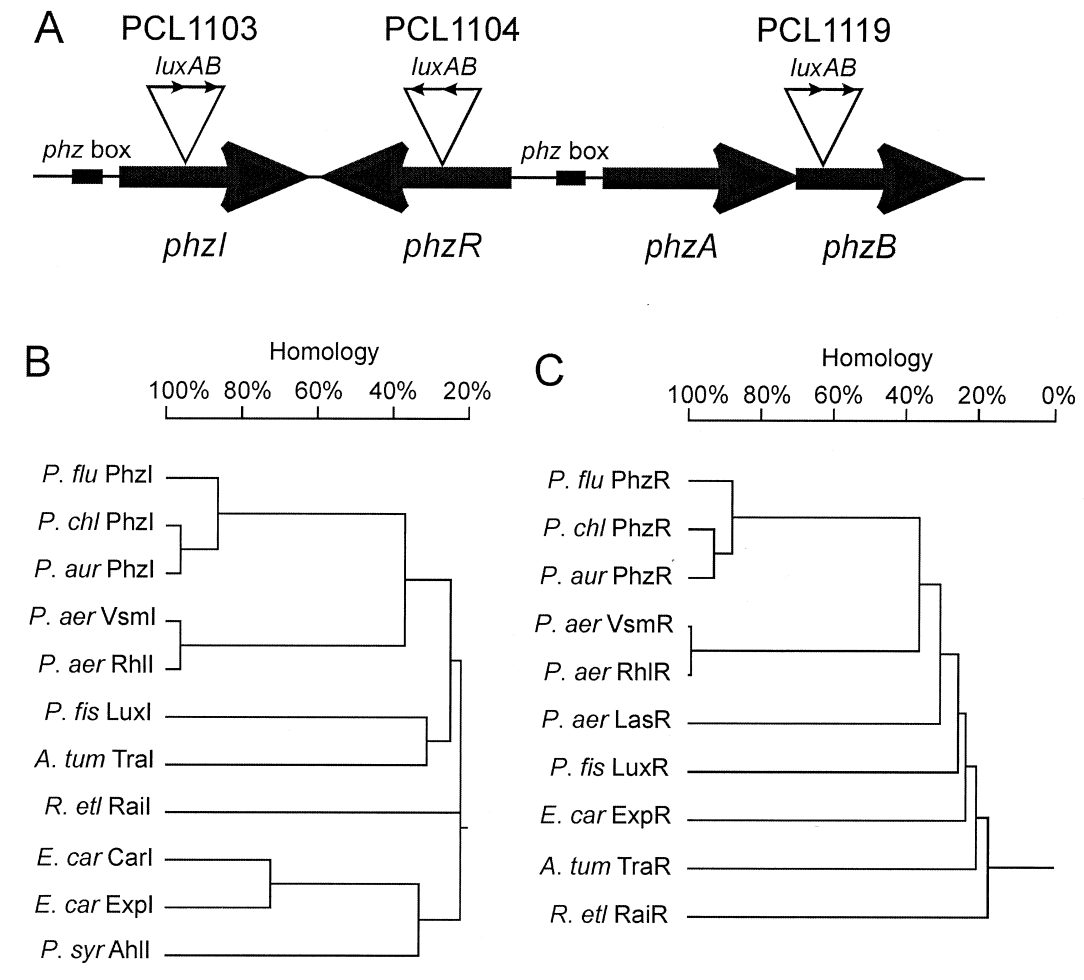

D

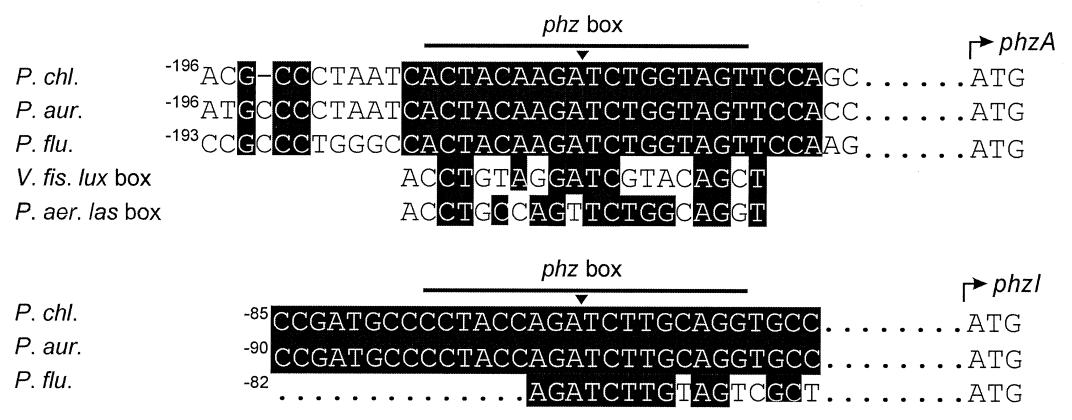

Fig. 3. Chromosomal localization, regulatory elements, and homology of gene products regulating phenazine-1-carboxamide (PCN) production in Pseudomonas chlororaphis PCL1391. A, Genetic analysis of mutants of $P$. chlororaphis strain PCL1391 lacking PCN production. Positions and orientations of the Tn5luxAB transposon of strains PCL1103, PCL1104, and PCL119 are indicated with arrows. The phzI and phzR and the first two genes of the PCN biosynthetic operon, $p h z A$ and $p h z B$, are shown. B, Tree of homology of the LuxI-homologous proteins of strain P. chlororaphis PCL1391 (P. chl. PhzI), Pseudomonas aureofaciens 30-84 (P. aur. PhzI), Pseudomonas fluorescens 2-79 (P. flu. PhzI), Pseudomonas aeruginosa (P. aer. VsmI and RhlI), Pseudomonas syringae pv. syringae (P. syr. AhlI), Vibrio fischeri (V. fis. LuxI), Erwinia carotovora (E. car. ExpI, CarI), Agrobacterium tumefaciens (A. tum. TraI), and Rhizobium etli (R. etl. RaiI). C, Homology tree of of the LuxR-homologous proteins of P. chlororaphis PCL1391 (P. chl. PhzI), P. aureofaciens 30-84 (P. aur. PhzR), P. fluorescens 2-79 (P. flu. PhzR), P. aeruginosa PAO1 (P. aer. VsmR, RhlR, LasR), V. fischeri (V. fis. LuxR), E. carotovora (E. car. ExpR), A. tumefaciens (A. tum. TraR), and R. etli (R. etl. RaiR). D, Identification of palindromic sequences in the phzI and phzA promoter regions of $P$. chlororaphis, $P$. aureofaciens 30-84, and P. fluorescens 2-79. The sequences and relative positions of the phz boxes and the ATG start codons of $p h z I$ and $p h z A$ are indicated. The lux box of $V$. fischeri and lux-like box of $P$. aeruginosa are aligned for comparison. Nucleotide sequences of the phzA promoter regions of $P$. aureofaciens 30-84 and $P$. fluorescens 2-79 were obtained from GenBank as accession nos. L48616 and AF007801, respectively. Nucleotide sequences of the phzI promoter regions are from GenBank sequences, accession nos. L33724 and L48616, respectively. Note that the $P$. fluorescens phzI promoter sequence was not completely available. 
amino acid sequences are highly homologous with the locus in the PCA-producing biocontrol strains P. fluorescens 2-79 and P. aureofaciens 30-84 (Fig. 3B and C). P. fluorescens 2-79 produces PCA (Mavrodi et al. 1997), whereas P. aureofaciens 30-84 produces hydroxy-phenazines in addition to PCA
(Pierson and Thomashow 1992). Despite the high similarities observed in the nucleotide sequences of the phzI genes in the three phenazine-producing species, the identities of the quorum-sensing signals appear to differ. P. aureofaciens 30-84 was reported only to produce $\mathrm{C}_{4}$-HSL and $\mathrm{C}_{6}$-HSL (Pierson
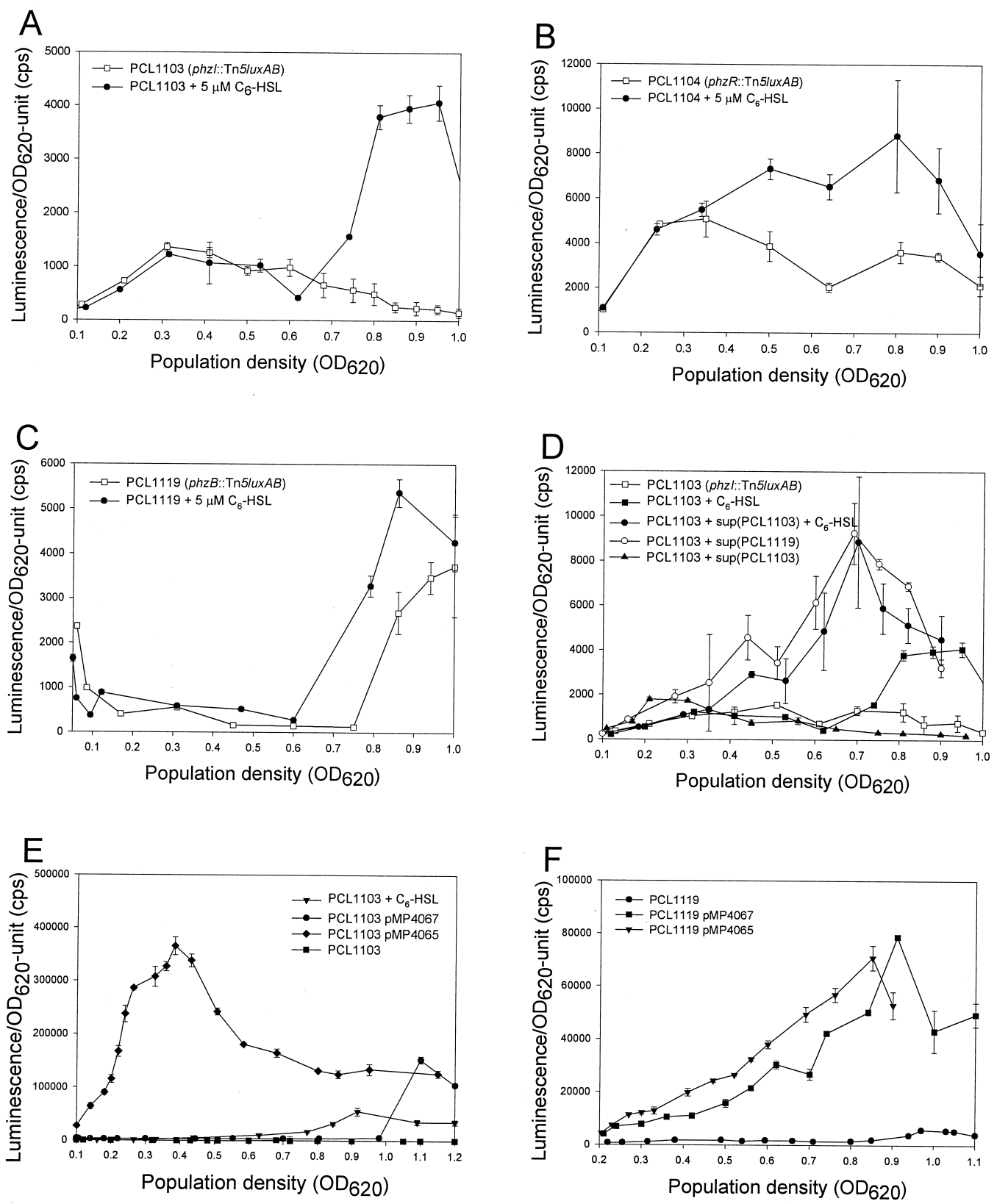

Fig 4. Expression analyses of the phzI gene, phzR gene, and the phenazine-1-carboxamide (PCN) biosynthetic operon of Pseudomonas chlororaphis strain PCL1391. Strains were grown in Luria-Bertani medium. $N$-hexanoyl-L-homoserine lactone $\left(\mathrm{C}_{6}\right.$-HSL) was added at the initial optical density (OD) at $620 \mathrm{~nm}$ of 0.1. Values depicted in the panels are values for the luminescence measured in counts per seconds (cps) per OD unit during growth in time. A, Expression of phzI in strain PCL1103 (phzI::Tn5luxAB) in the absence and presence of $5 \mu \mathrm{M}$ synthetic $\mathrm{C}_{6}$-HSL. B, phzR expression in the absence and presence of $5 \mu \mathrm{M}$ synthetic $\mathrm{C}_{6}$-HSL with strain PCL1104 (phzR::Tn5luxAB). C, Expression of the PCN biosynthetic operon of strain PCL1119 $(p h z B:: \operatorname{Tn} 5 \operatorname{lux} A B)$ in the absence and presence of $5 \mu \mathrm{M}$ synthetic $\mathrm{C}_{6}-\mathrm{HSL}$. D, Induction of phzI by synthetic $\mathrm{C}_{6}$-HSL, cell-free spent culture supernatant of strain PCL1103 (phzI::Tn5luxAB), spent growth supernatant of strain PCL1119 (phzB::Tn5luxAB), and a combination of spent growth supernatant of PCL1103 and $\mathrm{C}_{6}$-HSL. E, Expression of the PCN biosynthetic operon of strain PCL1119 ( $p h z B:$ :Tn5luxAB) harboring additional copies of phzI and $p h z R$. Multicopy plasmids pMP4065 (estimated copy number 30-40) and pMP4067 (estimated copy number 4-8) contain a 2.9-kb chromosomal fragment with the $p h z I$ and $p h z R$ genes. F, Expression of the $p h z I$ gene of strain PCL1103 ( $p h z I:: \operatorname{Tn} 5$ luxAB) harboring additional copies of $p h z I$ and $p h z R$ (pMP4065 and pMP4067) and expression of $p h z I$ in the absence and presence of $5 \mu \mathrm{M}$ synthetic $\mathrm{C}_{6}$-HSL. 
and Pierson 1996), whereas $P$. fluorescens 2-79 produced 3$\mathrm{OH}-\mathrm{C}_{6}-\mathrm{HSL}, 3-\mathrm{OH}-\mathrm{C}_{8}-\mathrm{HSL}, 3-\mathrm{OH}-\mathrm{C}_{10}-\mathrm{HSL}$, and $\mathrm{C}_{8}-\mathrm{HSL}$, yet hardly any $\mathrm{C}_{6}$-HSL (Cha et al. 1998).

Because members of the luxI and luxR family usually show weak homologies, the high similarities between the $p h z I-p h z R$ homologs indicate that this set of genes, which regulates antifungal metabolite production within these three Pseudomonas species, is evolutionary well conserved. Within or directly adjacent to the domain proposed to contain the amino acids involved in acyl-ACP selection in $V$. fischeri (amino acids 133 to 164 of LuxI) (Hanzelka et al. 1997), the amino acid sequence of $P$. chlororaphis is identical to that of $P$. aureofaciens, whereas the amino acids at positions $150,156,158$, and 159 differ in $P$. fluorescens. This is consistent with the observation that $P$. chlororaphis and $P$. aureofaciens mainly produce the $\mathrm{C}_{6}$-HSL signal (Wood and Pierson 1996), whereas $P$. fluorescens produces other autoinducer signals (Cha et al. 1998). In P. chlororaphis, PhzI and PhzR are more similar to the $p h z I$ and $p h z R$ gene products of $P$. aureofaciens than they are to those of $P$. fluorescens, which is consistent with the apparent closer relationship between the former two species (Krieg 1984).

$\mathrm{C}_{6}$-HSL clearly is involved in the regulation of PCN biosynthesis. First, PCN production was restored in the phzI mutant strain by the addition of either synthetic $\mathrm{C}_{6}$-HSL or of spent growth medium of strain PCL1391 to the cells or by providing phzI in trans. Second, from the series of synthetic HSLs tested (see below), only $\mathrm{C}_{6}$-HSL was able to advance expression of the reporter in PCL1119 (phzB::Tn5luxAB), showing that $\mathrm{C}_{6}$ HSL is involved in the expression of $p h z I$ (Fig. 4C). Nevertheless, this does not exclude the fact that other HSLs do play a role in regulating $\mathrm{PCN}$ biosynthesis and that some may even act as antagonists. Experiments in the lux, las, and tra systems have shown that noncognate HSLs or analogs have an agonistic or antagonistic effect when supplied in high concentrations (Puskas et al. 1997). We used multicopy plasmids to show that PCN production can be increased sixfold by introducing additional copies of the $p h z I$ and $p h z R$ genes. This resulted in an increased expression of the phzI gene (Fig. 4F), which was accompanied by an increased production of autoinducers secreted into the growth medium. We therefore explain the increased expression of the phz operon and increased amounts of PCN secreted into the growth medium are caused by the increased production of autoinducers. We believe that this is the first time that an increase of antibiotic production through the overproduction of HSLs is shown, which offers a new approach for increased antibiotic production in bacteria.

A palindromic sequence that is highly conserved in the promoter regions of the $p h z I$ and $p h z R$ genes of phenazineproducing Pseudomonas species was identified. We speculate that these phz boxes are binding sites for PhzR such as the palindromic lux box in $V$. fischeri, which was identified as a binding region for the transcriptional activator LuxR (Fig. 3D) (Devine et al. 1989; Shadel et al. 1990).

In addition to the dependence of $\mathrm{PCN}$ production on $\mathrm{C}_{6^{-}}$ HSL, the expression of phzI apparently requires so-farunidentified additional factor(s) secreted into the culture supernatant, as judged from the synergistic effect of spent growth medium from strain PCL1103 (phzI::Tn5luxAB) and synthetic $\mathrm{C}_{6}$-HSL (Fig. 4D). Upon the addition of $\mathrm{C}_{6}$-HSL at a density of $10^{8} \mathrm{CFU} / \mathrm{ml}$, the same delay in induction as seen with A. tumefaciens was observed, where induction occurred only after reaching late-exponential growth phase. This contrasts with the $V$. fischeri lux system. where induction is observed immediately (Eberhard et al. 1986; Nealson 1977). Wild-type expression levels of the PCN biosynthetic genes were reached only in the presence of the assumed second factor in the growth supernatant (Fig. 4D). Because strain PCL1391 also produces small amounts of $\mathrm{C}_{4}$ - $\mathrm{HSL}$ and $\mathrm{C}_{8^{-}}$ HSL, mixtures of $\mathrm{C}_{4}-\mathrm{HSL}, \mathrm{C}_{6}-\mathrm{HSL}$, and $\mathrm{C}_{8}-\mathrm{HSL}$ were tested for induction of the phzB::Tn5luxAB reporter. Neither $\mathrm{C}_{4}-\mathrm{HSL}$ nor $\mathrm{C}_{8}$-HSL influenced the induction in combination with $\mathrm{C}_{6}$ $\mathrm{HSL}$ at the concentrations added, indicating that the additional factor is different from these HSLs. No signals in addition to the ones that were detected in the Chromobacterium spp. $c v i$ system were observed with the Agrobacterium spp. tra sensor, which is more sensitive overall and responds to a broader spectrum of HSL molecules. This makes it less likely that oxo- or hydroxy-HSLs are responsible for the additional inducing activity. We speculate that the signal may be relayed into the cell by a GacS homolog, which is required for optimal production of autoinducers (Chin-A-Woeng et al., submitted).

$\mathrm{GacS}$ is a sensor kinase that operates closely together with the global regulator GacA (Rich et al. 1994). We also exclude the possibility that PCN itself is the additional factor needed to induce the expression of phzI at low cell densities because spent growth supernatant of strain PCL1119 $(p h z B:: \operatorname{Tn} 5 \operatorname{lux} A B)$, which does not produce PCN, was able to induce $p h z I$ expression. Apparently, the regulation mechanism differs from that of 2,4-diacetylphloroglucinol production, an antifungal factor produced by $P$. fluorescens $\mathrm{CHA} 0$ and other biocontrol strains, where the expression was induced by the final product (Schnider-Keel et al. 2000).

\section{MATERIALS AND METHODS}

\section{Microorganisms and media.}

The bacterial strains and plasmids used are listed in Table 1. $\mathrm{KB}$ medium was used for routine culturing of Pseudomonas spp. strains. E. coli and C. violaceum were grown in LB medium (Sambrook et al. 1989). A. tumefaciens was grown on yeast-extract mannitol broth (YMB) medium (Smit et al. 1987). Solid growth media contained $1.8 \%$ (wt/vol) agar (Difco Laboratories, Detroit, MI, U.S.A.). The antibiotic selection added, per ml, was $50 \mu \mathrm{g}$ of kanamycin, $80 \mu \mathrm{g}$ of tetracycline, $20 \mu \mathrm{g}$ of chloramphenicol, and $50 \mu \mathrm{g}$ of carbenicillin, where applicable.

\section{DNA modifications.}

Digestions with restriction endonucleases, ligation, and transformation of E. coli cells with plasmid DNA were performed with the use of standard molecular biological protocols (Sambrook et al. 1989). Nucleotide sequencing was performed by Eurogentec (Herstal, Belgium) with AB1377-based fluorescent sequencing technology. Computer analysis of protein and nucleotide sequences was achieved with the Wisconsin software package, version 10.0 (Genetics Computer Group, Madison, WI, U.S.A).

\section{PCN quantification, bioassays}

for hydrolytic activities, and root colonization.

PCN production was determined by extracting spent culture supernatants with an equal volume of toluene. The water 
phase was again extracted with toluene, the organic phases were pooled, and toluene was removed. Extracts were analyzed with HPLC, as described previously (Chin-A-Woeng et al. 1998). HCN was detected by cyanide-indicator paper (Castric 1975), protease with 5\% milk agar plates, lipase with Tween 80 agar plates (Howe and Ward 1976), and chitinase with agar plates containing colloidal chitin (Shimahara and Takiguchi 1988). The tomato root colonizing ability of the strains was performed as previously described (Simons et al. 1996). The strains were tested in competition with PCL1392, a lacZ-tagged derivative of strain PCL1391, with the same colonizing ability as the wild type (Chin-A-Woeng et al. 2000).

\section{Bioassays for autoinducer activity.}

To detect autoinducer activity with the $C$. violaceum HSL reporter assay (Milton et al. 1997), overnight cultures of $C$. violaceum CV026 were grown in LB medium supplemented with $50 \mu \mathrm{g}$ of kanamycin per ml. LB agar plates were overlaid with a $0.8 \%$ LB top agar layer mixed with a 16-h culture of $200 \mu \mathrm{l}$ of the $C$. violaceum CV026 indicator strain per $\mathrm{ml}$ (McClean et al. 1997). A 20- $\mu$ l volume of $100 \mu \mathrm{l}$ of extract or HPLC fraction was tested for autoinducer activity in wells punched into the agar. The activity of fractions was judged after $16 \mathrm{~h}$ of growth at $28^{\circ} \mathrm{C}$ by the appearance of a violet halo around the well caused by violascein production, which resulted from the activation of reporter genes in the $C$. violaceum strain. Autoinducer activity on C18 reverse-phase TLC (Merck, Darmstadt, Germany), developed in methanolwater $(60: 40, \mathrm{vol} / \mathrm{vol})$, was detected by overlaying the TLC plate with a $0.8 \%$ LB top agar layer containing CV026 cells, as described above, followed by incubation at $28^{\circ} \mathrm{C}$ for $16 \mathrm{~h}$ and analyzed for the appearance of violet spots.

The autoinducer indicator assay, developed on the basis of the Vibrio (lux) system with plasmid pSB401 (Winson et al. 1998), was conducted similarly to the assay described above for $C$. violaceum. A $50-\mu \mathrm{l}$ volume of a 16-h culture of DH5 $\alpha$ [pSB401] was mixed with $3.0 \mathrm{ml}$ of $0.8 \%$ LB top agar and poured onto LB agar plates containing $20 \mu \mathrm{g}$ of chloramphenicol per ml. A $20-\mu l$ volume of sample was placed in the wells, and the plates were incubated for $16 \mathrm{~h}$ at $28^{\circ} \mathrm{C}$. Luminescence was detected by placing photographic film (Fuji, Tokyo, Japan) against the bottom of the assay plates.

The induction of the Agrobacterium spp. tra system was detected with $A$. tumefaciens strain NT1 harboring plasmid pJM749, which contained a lacZ reporter fused to a tra gene, the expression of which is dependent on TraR (located on plasmid pSVB33) and the presence of a sufficient concentration of an autoinducer (Piper et al. 1993). Agrobacterium spp. was scraped from YMB plates 3 days after streaking and resuspended in sterile water to $\mathrm{OD}_{620}$ of 0.1 . A $100-\mu \mathrm{l}$ volume of the bacterial suspension was mixed with $3.0 \mathrm{ml}$ of top agar and poured onto YMB plates containing 5-bromo-4-chloro-3indolyl- $\beta$-galactopyranoside (X-Gal) to detect expression as blue pigmentation. Samples were tested as described above for the $C$. violaceum bioassay. Blue zones were visible after 24 to $48 \mathrm{~h}$ of incubation at $28^{\circ} \mathrm{C}$.

\section{Purification of autoinducers.}

To isolate autoinducer activity, 3 volumes of dichloromethane were added to 7 volumes of supernatant of a $72-\mathrm{h} \mathrm{KB}$ culture of PCL1119 and shaken for $1 \mathrm{~h}$ at $120 \mathrm{rpm}$. Following extraction, the organic phase was removed and dried by evaporation in vacuo (McClean et al. 1997). Crude supernatant extracts were redissolved in $100 \mu \mathrm{l}$ of $100 \%$ acetonitrile and fractionated with either $\mathrm{C}_{18}$ TLC or HPLC. $\mathrm{C}_{18}$-TLC plates (Merck) were developed in a solvent mixture of methanol-water (60:40, vol/vol). After development, the plates were dried and overlaid with a top agar layer containing one of the indicator strains and incubated for $16 \mathrm{~h}$ at $28^{\circ} \mathrm{C}$. HPLC was performed with a Hypersil octadecyl silane, $5 \mu \mathrm{m}, 250 \times 4.6$ mm column (Alltech Associates Deerfield, IL, U.S.A.) and a linear 20 to $90 \%$ ( $\mathrm{vol} / \mathrm{vol}$ ) gradient of acetonitrile in water with a flow rate of $1 \mathrm{ml}$ per min. After active fractions were selected, samples were pooled and reapplied to the column and eluted with an isocratic gradient of $35 \%$ acetonitrile. UV detection was performed with a RSD 2140 diode array detector (Pharmacia, Uppsala, Sweden) with wavelength scanning from 190 to $400 \mathrm{~nm}$, and $1.0 \mathrm{ml}$ fractions were collected and analyzed for the presence of autoinducer activity with the CV026 biosensor. Finally, active fractions were pooled for mass spectrometry analyses.

\section{Nanoelectrospray Q-TOF mass spectrometric analysis.}

Electrospray CID tandem mass spectra were obtained on a hybrid Q-TOF tandem mass spectrometer (Micromass, Wythenshawe, U.K.) equipped with a Z-Spray sample introduction system in a nanoflow electrospray ion source. The mass spectrometer was operated in the positive ion mode. The cone voltage was set at approximately $25 \mathrm{~V}$, and a capillary voltage of $1.5 \mathrm{kV}$ was used. Argon was used as the collision gas, and the spectra were obtained with a collision energy of $10 \mathrm{eV}$. Spectra were acquired via the TOF analyzer and were integrated every $2.4 \mathrm{~s}$ from $\mathrm{m} / \mathrm{z} 35$ to 250 . Data were recorded and processed with MassLynx software, version 3.1 (Micromass). Mass calibration was performed by multiple ion monitoring of singly charged sodium and cesium iodide signals. The samples were dissolved in $10 \mu \mathrm{l}$ of methanol, $3 \mu \mathrm{l}$ of which were loaded into the nanospray gold-coated glass capillary for sample delivery.

\section{Isolation of mutants impaired in PCN biosynthesis.}

A mutant library of PCL1391 was established with pRL1063a (Wolk et al. 1991), harboring a Tn5 transposon carrying promoterless $\operatorname{lux} A B$ reporter genes. Mutants were screened for the absence of or a change in pigment production on either LB agar plates or in $200-\mu l$ liquid $\mathrm{KB}$ cultures grown in 96-well microtiter plates for 3 days.

Because the Tn5 transposon in the transconjugants contains an origin of replication that functions in E. coli (Wolk et al. 1991), chromosomal DNA regions flanking the transposon were recovered from the genome by excision with EcoRI, followed by circularization, transfer to $E$. coli, and analysis by nucleotide sequencing. Nucleotide sequencing of the flanking regions was performed with unique primers oMP458 (5'-TACTAGATTCAATGCTATCAATGAG- $\left.3^{\prime}\right)$ and oMP459 (5'AGGAGGTCACATGGAATATCAGAT-3'), directed to the left and right ends of the Tn 5 transposon, respectively.

Isolation and identification of $l u x I$ and $l u x R$ homologs.

A plasmid library of chromosomal fragments of strain PCL1391 was constructed by cloning chromosomal DNA 
digested with EcoRI into the multicloning site of pBluescript (Stratagene, La Jolla, CA, USA) (Kragelund et al. 1995). After electroporation of this fragment library to an E. coli strain harboring the lux reporter pSB401 and overnight growth on LB agar plates, clones that induced the luciferase reporter were identified with photographic film. To cure the E. coli strain from the pSB401 reporter construct, chloramphenicol selection was omitted, whereas carbenicillin selection was maintained. The nucleotide sequence of the chromosomal insert in the remaining plasmid was determined with standard primers such as the universal and -40 reverse primer flanking the multiple cloning site of pBluescript. The plasmids pMP4067 and pMP4065 with the $p h z I$ and $p h z R$ genes were obtained by transferring 2.9-kb EcoRI-BamHI and HindIII subcloned fragments of pMP6007 to plasmids pME6010 and pBBR1MCS-5, respectively.

\section{Expression of bioluminescent Tn5luxAB reporter strains.}

Expression of Tn5luxAB-tagged genes was determined by quantification of bioluminescence during culturing. Cells from overnight cultures were washed with fresh medium and diluted to $\mathrm{OD}_{620}$ of 0.1 . Cultures were grown in LB medium in a volume of $10 \mathrm{ml}$ under vigorous shaking. Growth was followed by measurement of $\mathrm{OD}_{620}$ at regular intervals, and 100$\mu \mathrm{l}$ samples were taken in triplicate to quantify luminescence. A volume of $100 \mu \mathrm{l}$ of an $n$-decyl-aldehyde substrate solution (0.2\% $n$-decyl-aldehyde) (Sigma, St. Louis, MO, U.S.A.) in a $2.0 \%$ bovine serum albumin solution) was added. After thorough mixing, bioluminescence was determined with a MicroBeta 1450 TriLux luminescence counter (Wallac, Turku, Finland) and normalized to the luminescence per $\mathrm{OD}_{620}$ unit.

The synthetic HSL molecules $N$-butanoyl-L-homoserine lactone $\left(\mathrm{C}_{4}-\mathrm{HSL}\right), \mathrm{N}$-hexanoyl-L-homoserine lactone $\left(\mathrm{C}_{6}\right.$-HSL), $\mathrm{N}$ octanoyl-L-homoserine lactone $\left(\mathrm{C}_{8}\right.$-HSL $), \quad N$-decanoyl-Lhomoserine lactone $\left(\mathrm{C}_{10}\right.$-HSL $), \quad N$-dodecanoyl-L-homoserine lactone $\left(\mathrm{C}_{12}\right.$-HSL), $\mathrm{N}$-(3-oxo-hexanoyl)-L-homoserine lactone (3-oxo- $\mathrm{C}_{6}$-HSL), $\mathrm{N}$-(3-oxo-octanoyl)-L-homoserine lactone (3oxo- $\mathrm{C}_{8}$-HSL), and $\mathrm{N}$-(3-oxo-decanoyl)-L-homoserine lactone (3oxo- $\mathrm{C}_{10}$-HSL) were tested for the ability to induce $\operatorname{Tn} 5 \operatorname{lux} A B$ reporter strains. Cells were grown overnight in LB medium, washed, and resuspended to $\mathrm{OD}_{620}$ of 0.1 in fresh medium supplemented with either $5 \mu \mathrm{M}$ synthetic HSL(s) or $10 \%$ (vol/vol) spent growth supernatant and grown to stationary phase. Luminescence was determined after every $0.1 \mathrm{U}$ increase of $\mathrm{OD}_{620}$ and compared with the control without added HSL.

\section{ACKNOWLEDGMENTS}

We thank P. Williams of the University of Nottingham for kindly providing the synthetic autoinducers and reporter strains. We thank A. La Rose for his help in part of the experiments. T. F. C. Chin-A-Woeng was supported partly by EU biotechnology grant BI04-CT96.0181. J. E. ThomasOates gratefully acknowledges financial support (S. J. Gaskell and R. J. Beynon) from the Higher Education Funding Council for England, with additional support from Smith Kline Beecham, UMIST, the University of Wales College of Medicine, and Chugai Pharmaceuticals for the purchase of the UMIST Q-TOF, and The Netherlands Foundation for Chemical Research (SON) with financial aid from The Netherlands Organization for Scientific Research (NWO) for the purchase of the Utrecht Q-TOF.

\section{LITERATURE CITED}

Antoine, R., and Locht, C. 1992. Isolation and molecular characterization of a novel broad-host-range plasmid from Bordetella bronchisep- tica with sequence similarities to plasmids from gram-positive organisms. Mol. Microbiol. 6:1785-1799.

Boyer, H. W., and Roulland-Dussoix, D. 1969. A complementation analysis of the restriction and modification of DNA in Escherichia coli. J. Mol. Biol. 41:459-472.

Castric, P. A. 1975. Hydrogen cyanide, a secondary metabolite of Pseudomonas aeruginosa. Can. J. Microbiol. 21:613-618.

Cha, C., Gao, P., Chen, Y.-C., Shaw, P. D., and Farrand, S. K. 1998. Production of acyl-homoserine lactone quorum-sensing signals by gram-negative plant-associated bacteria. Mol. Plant-Microbe Interact. 11:1119-1129.

Chin-A-Woeng, T. F. C., Thomas-Oates, J. E., Lugtenberg, B. J. J., and Bloemberg, G. V. 2001. Introduction of the $p h z H$ Gene of Pseudomonas chlorophis PCL1391 Extends the range of biocontrol ability of phenazine-1-carboxylic acid-producing Pseudomonas spp. strains. Mol. Plant-Microbe Interact. 14:1006-1015.

Chin-A-Woeng, T. F. C., Bloemberg, G. V., Van der Bij, A. J., Van der Drift, K. M. G. M., Schripsema, J., Kroon, B., Scheffer, R. J., Keel, C., Bakker, P. A. H. M., Tichy, H.-V., De Bruijn, F. J., Thomas-Oates, J. E., and Lugtenberg, B. J. J. 1998. Biocontrol by phenazine-1carboxamide-producing Pseudomonas chlororaphis PCL1391 of tomato root rot caused by Fusarium oxysporum f. sp. radicislycopersici. Mol. Plant-Microbe Interact. 11:1069-1077.

Chin-A-Woeng, T. F. C., Bloemberg, G. V., Mulders, I. H. M., Dekkers, L. C., and Lugtenberg, B. J. J. 2000. Root colonization by phenazine1-carboxamide-producing bacterium Pseudomonas chlororaphis PCL1391 is essential for biocontrol of tomato foot and root rot. Mol. Plant-Microbe Interact. 13:1340-1345.

Devine, J. H., Shadel, G. S., and Baldwin, T. O. 1989. Identification of the operator of the lux regulon from the Vibrio fischeri strain ATCC7744. Proc. Natl. Acad. Sci. USA 86:5688-5692.

Eberhard, A., Widrig, C. A., McBath, P., and Schineller, J. B. 1986. Analogs of the autoinducer of bioluminescence in Vibrio fischeri. Arch. Microbiol. 146:35-40.

Fuqua, W. C., Winans, S. C., and Greenberg, E. P. 1994. Quorum sensing in bacteria: The LuxR-LuxI family of cell density-responsive transcriptional regulators. J. Bacteriol. 176:269-275.

Geels, F. P., and Schippers, G. 1983. Selection of antagonistic fluorescent Pseudomonas spp. and their root colonization and persistence following treatment of seed potatoes. Phytopathol. Z. 108:193-206.

Hanzelka, B. L., and Greenberg, E. P. 1996. Quorum sensing in Vibrio fischeri: Evidence that $S$-adenosylmethionine is the amino acid substrate for autoinducer synthesis. J. Bacteriol. 178:5291-5294.

Hanzelka, B. L., Stevens, A. M., Parsek, M. R., Crone, T. J., and Greenberg, E. P. 1997. Mutational analysis of the Vibrio fischeri luxI polypeptide: Critical regions of an autoinducer synthase. J. Bacteriol. 179:4882-4887.

Heeb, S., Itoh, Y., Nishijyo, T., Schnider, U., Keel, C., Wade, J., Walsh, U., O'Gara, F., and Haas, D. 2000. Small, stable shuttle vectors based on the minimal pVS1 replicon for use in gram-negative, plantassociated bacteria. Mol. Plant-Microbe Interact. 13:232-237.

Howe, T. R., and Ward, J. M. 1976. The utilization of Tween 80 as carbon source by Pseudomonas. J. Gen. Microbiol. 92:234-235.

Hwang, I., Cook, D. M., and Farrand, S. K. 1995. A new regulatory element modulates homoserine lactone-mediated autoinduction of $\mathrm{Ti}$ plasmid conjugal transfer. J. Bacteriol. 177:449-458.

King, E. O., Ward, M. K., and Raney, D. E. 1954. Two simple media for the demonstration of pyocyanin and fluorescein. J. Lab. Clin. Med. 44:301-307.

Krieg, N. R. 1984. Bergey's Manual of Systematic Bacteriology. Williams \& Wilkins, Baltimore.

Mavrodi, D. V., Ksenzenko, V. N., Chatuev, B. M., Thomashow, L. S., and Boronin, A. M. 1997. Structural and functional organization of Pseudomonas fluorescens genes encoding enzymes of phenazine-1carboxylic acid biosynthesis. Mol. Biol. 31:62-68.

McClean, K. H., Winson, M. K., Fish, L., Taylor, A., Chhabra, S. R., Camara, M., Daykin, M., Lamb, J. H., Swift, S., Bycroft, B. W., Stewart, G. B., and Williams, P. 1997. Quorum sensing and Chromobacterium violaceum: Exploitation of violacein production and inhibition for the detection of $N$-acylhomoserine lactones. Microbiology 143:3703-3711.

Milton, D. L., Hardman, A., Camara, M., Chhabra, S. R., Bycroft, B. W., Stewart, G. B., and Williams, P. 1997. Quorum sensing in Vibrio anguillarum: Characterization of the vanI/vanR locus and identification 
of the autoinducer $N$-(3-oxodecanoyl)-L-homoserine lactone. J. Bacteriol. 179:3004-3012.

Nealson, K. H. 1977. Autoinduction of bacterial luciferase. Occurrence, mechanism and significance. Arch. Microbiol. 112:73-79.

Parsek, M. R., Val, D. L., Hanzelka, B. L., Cronan, J. E., and Greenberg, E. P. 1999. Acyl homoserine-lactone quorum-sensing signal generation. Proc. Natl. Acad. Sci. USA 96:4360-4365.

Pearson, J. P., Van-Delden, C., and Iglewski, B. H. 1999. Active efflux and diffusion are involved in transport of Pseudomonas aeruginosa cell-to-cell signals. J. Bacteriol. 181:1203-1210.

Pierson, L. S., III, and Thomashow, L. S. 1992. Cloning and heterologous expression of the phenazine biosynthetic locus from Pseudomonas aureofaciens 30-84. Mol. Plant-Microbe Interact. 5:330-339.

Pierson, L. S., and Pierson, E. A. 1996. Phenazine antibiotic production in Pseudomonas aureofaciens: Role in rhizosphere ecology and pathogen suppression. FEMS Microbiol. Lett. 136:101-108.

Piper, K. R., Beck von Bodman, S., and Farrand, S. K. 1993. Conjugation factor of Agrobacterium tumefaciens regulates Ti plasmid transfer by autoinduction. Nature 362:448-450.

Puskas, A., Greenberg, E. P., Kaplan, S., and Schaeffer, A. L. 1997. A quorum-sensing system in the free-living photosynthetic bacterium Rhodobacter sphaeroides. J. Bacteriol. 179:7530-7537.

Rich, J. J., Kinscherf, T. G., Kitten, T., and Willis, D. K. 1994. Genetic evidence that the gacA gene encodes the cognate response regulator for the lemA sensor in Pseudomonas syringae. J. Bacteriol. 176:7468-7475.

Salmond, G. P. C., Bycroft, B. W., Stewart, G. S. A. B., and Williams, P. 1995. The bacterial "enigma": Cracking the code of cell-cell communication. Mol. Microbiol. 16:615-624.

Sambrook, J., Fritsch, E. F., and Maniatis, T. 1989. Molecular Cloning: A Laboratory Manual. Cold Spring Harbor Laboratory, Cold Spring Harbor, NY, U.S.A.

Schaefer, A. L., Val, D. L., Hanzelka, B. L., Cronan, J. E., and Greenberg, E. P. 1997. Generation of cell to cell signals in quorum sensing: Acyl homoserine lactone synthase activity of a purified $\mathrm{Vi}$ brio fischeri LuxI protein. Proc. Natl. Acad. Sci. USA 93:9505-9509.

Schnider-Keel, U., Seematter, A., Maurhofer, M., Blumer, C., Duffy, B., Gigot-Bonnefoy, C., Reimmann, C., Notz, R., Defago, G., Haas, D., and Keel, C. 2000. Autoinduction of 2,4-diacetylphloroglucinol bio- synthesis in the biocontrol agent Pseudomonas fluorescens $\mathrm{CHA} 0$ and repression by the bacterial metabolites salicylate and pyoluteorin. J. Bacteriol. 182:1215-1225.

Shadel, G. S., Devine, J. H., and Baldwin, T. O. 1990. Control of the lux regulon of Vibrio fischeri. J. Biolumin. Chemilumin. 5:99-106.

Shimahara, K., and Takiguchi, Y. 1988. Preparation of crustacean chitin. Pages 417-423 in: Methods in Enzymology. W. A. Wood and S. T. Kellog, eds. Academic Press, San Diego.

Simons, M., Van der Bij, A. J., Brand, J., De Weger, L. A., Wijffelman, C. A., and Lugtenberg, B. J. J. 1996. Gnotobiotic system for studying rhizosphere colonization by plant growth-promoting Pseudomonas bacteria. Mol. Plant-Microbe Interact. 9:600-607.

Smit, G., Kijne, J. W., and Lugtenberg, B. J. J. 1987. Both cellulose fibrils and a $\mathrm{Ca}^{2+}$-dependent adhesin are involved in the attachment of Rhizobium leguminosarum to pea root hair tips. J. Bacteriol. 169:4294-4301.

Stevens, A. M., and Greenberg, E. P. 1997. Quorum sensing in Vibrio fischeri: Essential elements for activation of the luminescence genes. J. Bacteriol. 179:557-562.

Winson, M. K., Swift, S., Fish, L., Throup, J. P., Jorgensen, F., Chhabra, S. R., Bycroft, B. W., Williams, P., and Stewart, G. S. 1998. Construction and analysis of luxCDABE-based plasmid sensors for investigating $N$-acyl-homoserine lactone-mediated quorum sensing. FEMS Microbiol. Lett. 163:185-192.

Wolk, C. P., Cai, Y., and Panoff, J. M. 1991. Use of a transposon with luciferase as a reporter to identify environmentally responsive genes in a cyanobacterium. Proc. Natl. Acad. Sci. USA 88:5355-5359.

Wood, D. W., and Pierson, L. S. 1996. The phzI gene of Pseudomonas aureofaciens 30-84 is responsible for the production of a diffusible signal required for phenazine antibiotic production. Gene 168:49-53.

Wood, D. W., Gong, F. C., Daykin, M. M., Williams, P., and Pierson, L. S. 1997. $N$-acyl-homoserine lactone-mediated regulation of phenazine gene expression by Pseudomonas aureofaciens 30-84 in the wheat rhizosphere. J. Bacteriol. 179:7663-7670.

Zhu, J., and Winans, S. C. 1999. Autoinducer binding by the quorumsensing regulator TraR increases affinity for target promoters in vitro and decreases TraR turnover rates in whole cells. Proc. Natl. Acad. Sci. USA 96:4832-4837. 